\title{
Primary mucinous ovarian tumors vs. ovarian metastases from gastrointestinal tract, pancreas and biliary tree: a review of current problematics
}

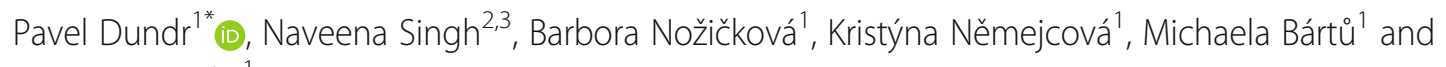
Ivana Stružinská ${ }^{1}$

\begin{abstract}
Background: Making the distinction between primary mucinous and metastatic ovarian tumors is often difficult, especially in tumors with a primary source from the gastrointestinal tract, pancreas and biliary tree. The aim of the following paper is to provide an overview of the problematics, with a focus on the possibilities of the differential diagnosis at the macroscopic, microscopic and immunohistochemical level.

Main body: The three main aspects of mucinous ovarian tumors are described in detail, including the comparison of the available diagnostic algorithms based on the evaluation of mostly macroscopic features, characterization of the spectrum of microscopic features, and a detailed analysis of the immunophenotype comparing 20 antibodies with the assessment of their statistical significance for differential diagnosis purposes. Specific features, including Krukenberg tumor and pseudomyxoma peritonei, are also discussed.

Conclusion: Despite the growing knowledge of the macroscopic and microscopic features of ovarian mucinous tumors and the availability of a wide range of immunohistochemical antibodies useful in this setting, there still remains a group of tumors which cannot be precisely classified without close clinical-pathological cooperation.
\end{abstract}

Keywords: Ovarian tumors, Mucinous carcinoma, Mucinous borderline tumor, Ovarian metastases

\section{Introduction}

According to historical data, primary mucinous ovarian carcinomas (MC) accounted for about $12 \%$ of all ovarian carcinomas [1]. However, some of the historical data was also in contradiction with this high reported incidence of MC, such as the results of the Surveillance Epidemiologic and End Results (SEER) study. In this study, which analyzed data from 1978 to 1998, only $1 \%$ (3508 of 35,059$)$ of invasive ovarian cancers were

\footnotetext{
* Correspondence: pavel.dundr@vfn.cz

${ }^{1}$ Institute of Pathology, First Faculty of Medicine, Charles University and General University Hospital in Prague, Studničkova 2, 12800 Prague 2, Czech Republic

Full list of author information is available at the end of the article
}

classified as mucinous carcinomas [2]. The results of this study are difficult to interpret, as the percentage of mucinous ovarian carcinomas was extremely low, even when taking into consideration the current knowledge showing lower incidence of MC than historically thought. In approximately the last two decades a lower incidence of MC than which had been previously reported has been confirmed. It has been shown that a significant proportion of $\mathrm{MC}$ or mucinous borderline tumors (MBT) of the ovary, which were originally classified as primarily ovarian, are actually of metastatic origin with the primary source located most commonly in the gastrointestinal tract [3]. Based on this data, it seems 
that MCs are rare tumors, representing approximately $3 \%$ of all ovarian cancers. For this reason, any data gained from studies of primary ovarian mucinous tumors which were conducted prior to the 1990s should be viewed with caution, as the likelihood that these studies inadvertently included metastatic tumors is high. However, the distinction between primary mucinous ovarian tumor and a metastasis can be difficult even today. There is still a certain proportion of tumors for which, based on the morphological and immunohistochemical (IHC) features alone, the distinction between a primary and a metastatic tumor is not possible. These tumors require a close clinical-pathological cooperation. The reason for this is that the tumor morphology, IHC features, and even the molecular changes of primary and metastatic tumors may overlap. This applies in particular to cases where metastases to the ovary are clinically apparent before the manifestation of the primary tumor, which may not be detectable at the time of diagnosis, even by the available imaging methods. The approach to the differential diagnosis of these tumors is complex and includes a combination of macroscopic, microscopic, and IHC features. In our review we provide a comprehensive summary of ovarian mucinous tumors focusing on those morphological features which may be helpful in differential diagnosis, including macroscopy, microscopy, and IHC characteristics. The goal of our review is to provide a comprehensive overview of current published data, focusing especially on the algorithmic approach to distinction between primary and metastatic ovarian tumors. Concerning the IHC profile of ovarian mucinous tumors, we performed an extensive literature search in order to prepare a complex, although nonexhaustive review to assess the practical significance of immunohistochemistry in the differential diagnosis of these tumors.

\section{Methods}

An extensive review of the literature on the subject of primary mucinous ovarian cancer and metastatic ovarian tumors was carried out. The data was obtained through a database search using a combination of the $\mathrm{MeSH}$ (Medical Subject Headings) terms "mucinous", "carcinoma", "ovary", "ovarian", "immunohistochemistry", "primary" and "metastatic". The data was mined from the PubMed/MEDLINE database covering the time period from 1985 to May 2020. The first search resulted in 11, 906 articles. From these the duplicates, articles evidently not relevant to the topic, and case reports were excluded based on the title and revision of the abstract. After that we selected a group of 536 articles which were screened in their entirety in order to select articles relevant to our study. All articles describing the IHC results in a group of ovarian cancer without further specification and possibility of precise allocation of the results to the particular histological type (i.e. mucinous carcinoma) were either excluded, or used only to mine data concerning metastases. Data concerning the endocervical type of mucinous borderline tumors, seromucinous borderline tumors, and endometrioid tumors with mucinous differentiation was excluded. Finally, we selected 49 studies which focus on the problematics of IHC characteristics of primary mucinous ovarian tumors, and/or ovarian metastases and their corresponding primary gastrointestinal tract (GIT), pancreas or biliary tree sources, which are the basis of this review concerning immunohistochemical analyses [4-52]. After excluding both antibodies where the staining results were not available for both primary and metastatic tumors, and antibodies used on a very limited number of cases, 20 primary antibodies were selected for further analysis as the subject of this study. The list of all the included antibodies is provided in Table 1. We should however be aware that different studies may use different clones of the same antibody which may not necessarily result in the same staining. This facts represent a limitation of our review.

The data extracted from these studies was analyzed with a focus on the following parameters: the number of all cases, the number of positive and negative cases, and the extent of positivity (divided into categories $1+, 2+$, and 3+). However, the criteria for IHC result categorization often differ among the studies analyzed, so only the $3+$ positivity was selected for a further subanalysis (this category was used to cover cases with "diffuse expression" or positive expression in $>50 \%$ cells irrespectively of the staining intensity). The percentage of all positive cases and $3+$ positive cases was calculated for all the categories when available. For the purposes of the statistical analysis, we compared all mucinous ovarian tumors merged into one category as "primary mucinous tumors" (including mucinous cystadenoma, borderline tumor, and carcinoma) with 5 groups of other tumors. These were classified into: "colorectal carcinoma", "appendiceal carcinoma", "pancreatic carcinoma", "pancreatobiliary carcinoma" and "gastric carcinoma". This classification was designed due to the wide range of different stratifications of tumors in the selected studies (some of which, for example, reported only joined groups such as "pancreatobiliary", others used categories like "pancreatic", "extrahepatic biliary", etc.). We feel that especially the category of appendiceal tumors deserves a separate assessment for appendiceal carcinoma and low grade appendiceal mucinous neoplasm (LAMN). Unfortunately, most of the studies merged these two categories into one group of tumors, and as such precise allocation of the result to either appendiceal carcinoma or LAMN was not possible. For studies using the joined 


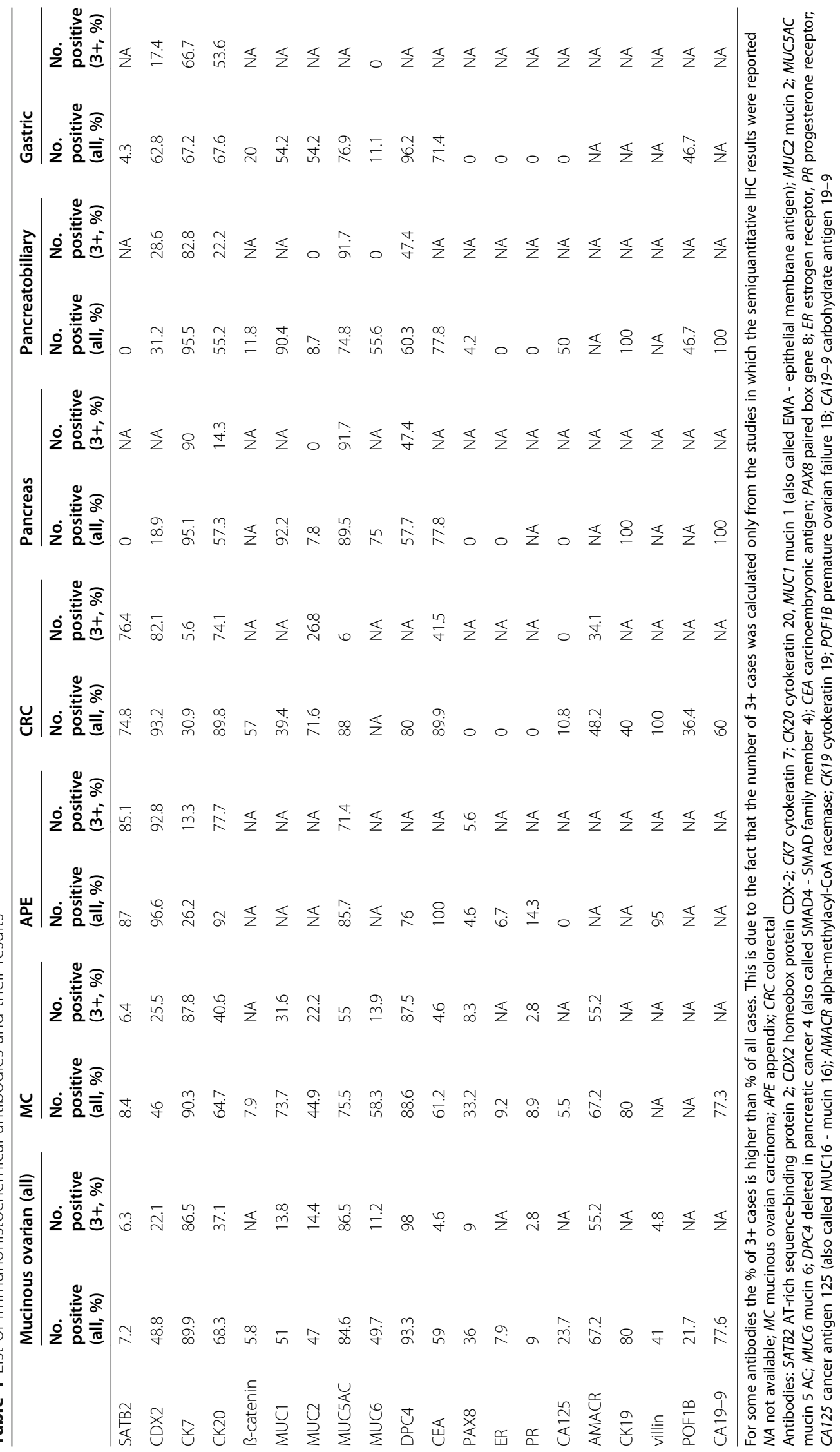


groups of tumors, the results for both extraovarian primary tumors (i.e. colorectal carcinoma) and metastatic tumors (i.e. ovarian metastasis of colorectal carcinoma) were merged. The results reported only in broader categories, such as "upper GI tract", were excluded from our review. The number of positive/negative cases (recorded values) was statistically compared between the "primary mucinous tumors" and the five groups of metastatic tumors for all of the 20 antibodies, using the Pearson Chi-square test or Fisher's Exact test, depending on the expected values [53, 54]. Statistical analyses were performed using the software TIBCO Statistica 13.3.0. All tests were two-sided and a $p$-value of less than 0.05 was considered as significant.

The data concerning the algorithmic approach to differential diagnosis is based on the results of 11 studies $[3,13,16,55-62]$. The general macroscopic and microscopic features of primary and metastatic ovarian tumors were extracted from several studies, including the review articles.

\section{Macroscopic and microscopic features of mucinous ovarian tumors}

Both primary and metastatic mucinous ovarian tumors are characterized by a number of macroscopic and microscopic features, which may be helpful in their differential diagnosis (Figs. 1, 2 and 3). However, these are not entirely specific and a subset of metastatic tumors may sometimes mimic primary ovarian tumors $[3,8,55$, $63,64]$. In general, most primary ovarian mucinous carcinomas are large, unilateral tumors that are cystic, multilocular, with intact smooth surface, without any nodularities. Cystic and solid areas in these tumors are evenly distributed throughout the tumor. Areas with features of benign mucinous cystadenoma or MBT are common. The predominant type of invasion is usually
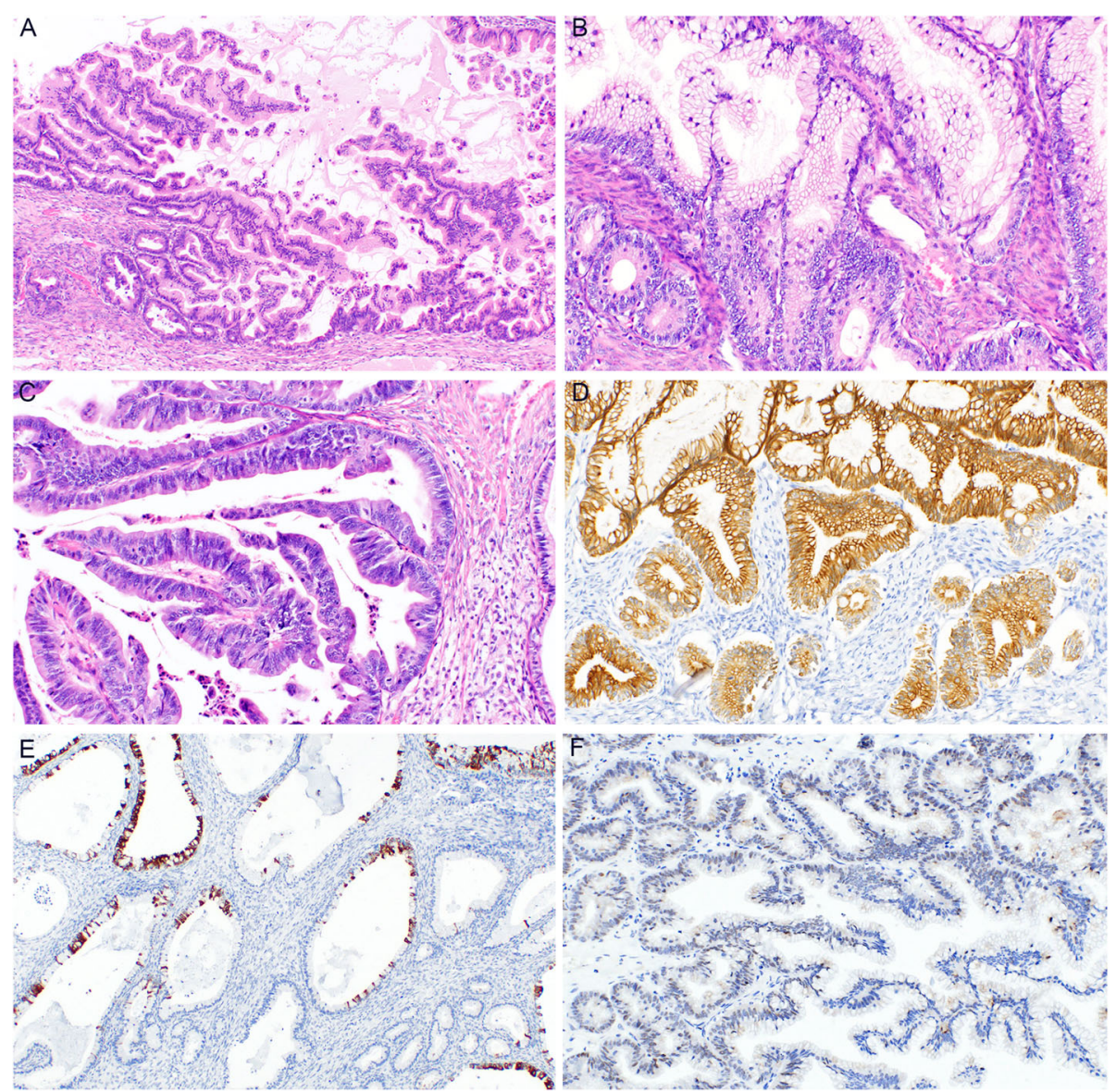

Fig. 1 Mucinous borderline tumor (MBT). Intracystic epithelial proliferation of gastrointestinal-type epithelium with villoglandular arrangement (a) (H\&E, 100x). Tumor structures showing increased proliferative activity in the crypts with mitoses and mild nuclear atypia, whereas other parts of the villoglandular structures consist of more mature cells (b) (H\&E, 200x). MBT with intraepithelial carcinoma consisting of tumor cells with marked nuclear atypia and increased mitotic activity (c) (H\&E, 200x). Diffuse immunohistochemical expression of cytokeratin 7 (d) (200x) and focal expression of cytokeratin 20 (e) (200x). MBT with focal, mostly weak expression of PAX8 (f) (200x) 


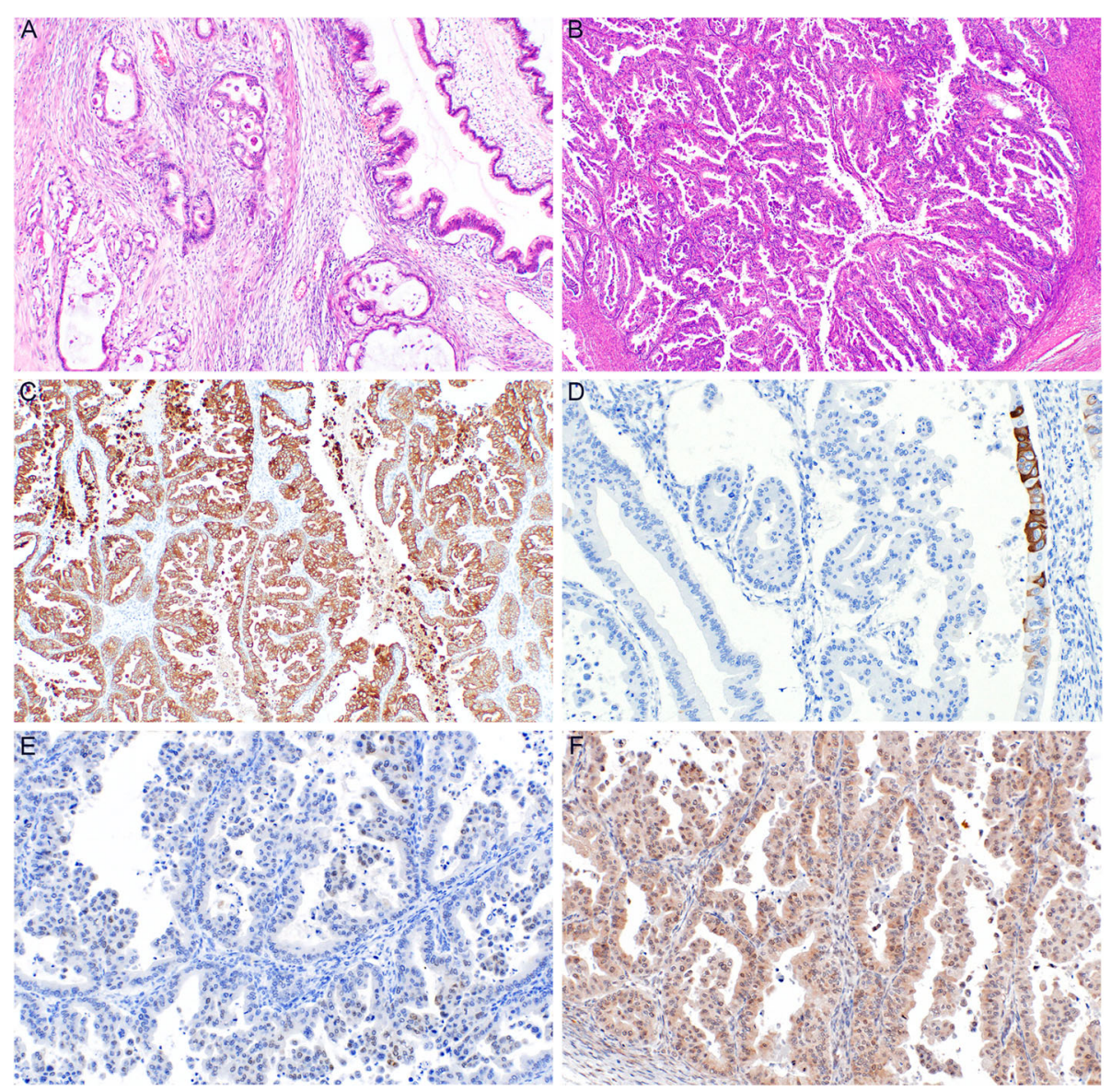

Fig. 2 Mucinous carcinoma of the ovary (MC). Infiltrative type of invasion with glandular and cribriform areas (a) (H\&E, 100x). Expansile type of invasion with areas of complex glandular proliferation (b) (H\&E, 40x). Diffuse expression of cytokeratin 7 (c) (100x) and focal expression of cytokeratin 20 (d) (200x). Focal and weak expression of PAX8 (e) (200x). Tumor cells showing retained expression of DPC4 (f) (200x)

expansile, with the infiltrative type of invasion being absent or only focal in most cases. On the contrary, metastatic tumors are often smaller, bilateral, and involve the ovarian surface or superficial cortex. The nodularity is usually visible macroscopically, however, even cases without macroscopically distinct nodules usually show these at a microscopic level, where they are characterized by aggregates (groups, nodules) of tumor cells surrounded by normal ovarian stroma, especially in the superficial cortex. Another feature which seems to be relatively specific for ovarian metastasis of LAMN is gross mucinous multinodular appearance [65]. Metastatic tumors also often show a predominantly infiltrative type of invasion. However, some metastases (especially of pancreatobiliary tract malignancies) are known to often mimic primary ovarian tumors $[8,17$, $66,67]$. These tumors commonly show areas of benign or MBT appearance. Some tumors even consist only of these areas and do not show any areas of invasive growth (so-called paradoxical maturation). Metastatic tumors of pure MBT appearance are typically characterized by more pronounced nuclear atypia, and the lesions mimic an MBT with intraepithelial carcinoma. Moreover, even metastatic tumors can be large, unilateral, and even without surface involvement. According to our review, in studies in which this data was available, unilateral tumors $\geq 10 \mathrm{~cm}$ represent $15 \%$ of all metastatic tumors (29/190 cases; range 5-19.8\%). These tumors are particularly difficult to diagnose as metastatic, especially in cases when they represent the first manifestation of a hitherto clinically occult primary extraovarian disease.

A summary of the morphological features is given in Table 2, although there is no single feature which would allow for a clear distinction between a primary and a metastatic tumor. For example laterality, which is cited as one of the key features when distinguishing between primary (mostly unilateral) and metastatic (more often bilateral) tumors, is by itself a highly unreliable feature. As with other parameters, historical data concerning mucinous carcinomas should be viewed with caution. For example, in a study published in 2005 analyzing the 

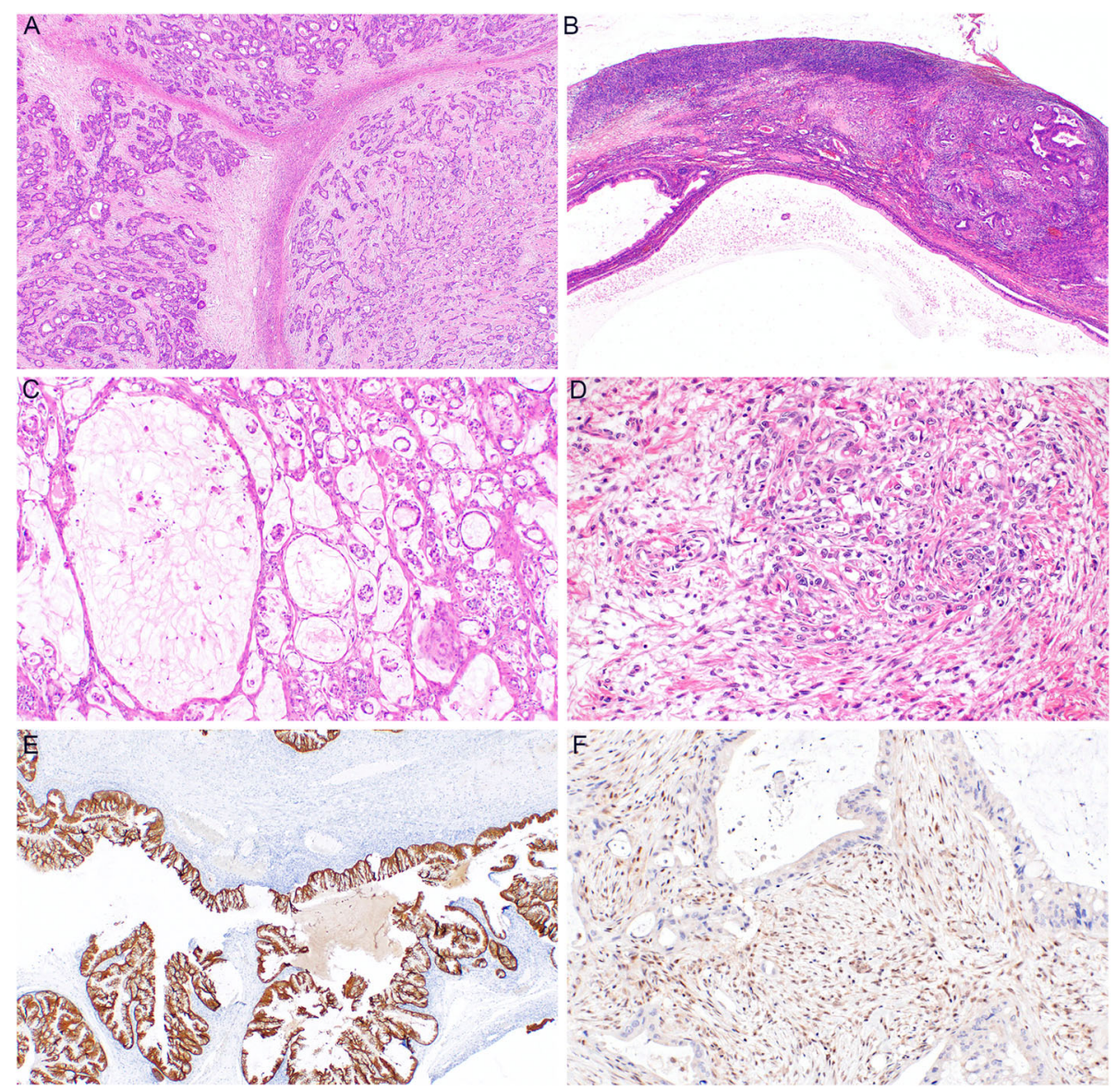

Fig. 3 Ovarian metastases from GIT tumors. Metastasis of colorectal carcinoma showing nodular arrangement (a) (H\&E, 40x). Metastasis of pancreatic carcinoma with areas of benign appearance and a nodule of infiltrative growth (b) (H\&E, 40x). Gallbladder metastasis with infiltrative growth of irregular glands (c) (H\&E, 100x). Metastases of gastric carcinoma with typical appearance of Krukenberg tumor with

"pseudosarcomatous" stromal reaction (d) (200x). Ovarian metastasis of appendiceal low grade mucinous neoplasm showing positivity of cytokeratin 20 (e) (40x). Pancreatic metastasis showing loss of DPC4 expression (f) (200x)

data from the Surveillance Epidemiologic and End Results (SEER) program (which included data from 22,328 women with ovarian cancer without central evaluation from the period between 1992 and 2000), MC was reported as bilateral in 355/1665 cases (21.3\%) regardless of the disease stage [68]. The high percentage of primary bilateral tumors suggests that some of these tumors were probably of a metastatic origin. Based on our analysis of the data, which we performed using the data mined from 26 studies dealing with this issue, bilaterality was found in $9.4 \%$ of all primary mucinous ovarian tumors (104/ $1105)$, in $10.3 \%$ of MC (95/918) and in $49.7 \%$ of metastases $(1176 / 2365)$, regardless of the primary source $[3,17$, $20,23,34,38,46,47,55,60-62,66,67,69-80]$. However, when evaluating colorectal cancer metastases separately, bilaterality was found in only $25.8 \%$ of cases (25/ 97). Still, the percentage of bilateral primary ovarian tumors $(10.3 \%$ of primary $\mathrm{MC})$ seems to be too high and the possibility that some studies may be biased by metastatic ovarian tumors misclassified as primary tumors cannot be excluded with certainty. Tumor laterality alone is not sufficient enough to distinguish between primary and metastatic tumors, and a careful evaluation which takes into consideration other tumor features is necessary. However, laterality is still one of the key parameters evaluated in the algorithmic approaches (usually in combination with the size of the tumor), which are discussed in detail below.

One of the features which deserves a special recognition because of its high specificity for metastatic origin is the presence of signet ring cells. Tumors containing signet ring cells are, in keeping with stringent diagnostic criteria regardless of their primary source, referred to as Krukenberg tumors. By definition, a Krukenberg tumor is a tumor in which, in addition to signet ring cells, the tumor stroma is often present in the form of a "sarcomatoid" stromal reaction [81, 82]. Krukenberg, after whom the tumor is named, hypothesized that it was an unusual 
Table 2 List of morphological features of primary and metastatic ovarian carcinomas

\begin{tabular}{|c|c|c|}
\hline Favor primary & Favor metastatic & Unhelpful features \\
\hline smooth capsule & involvement of surface and superficial cortex & gross cysts \\
\hline $\begin{array}{l}\text { evenly distributed cystic and solid areas } \\
\text { (no discrete nodularity) }\end{array}$ & $\begin{array}{l}\text { nodular pattern (gross and/or microscopic) including gross mucinous } \\
\text { multinodular appearance }\end{array}$ & $\begin{array}{l}\text { gross solid, papillary, } \\
\text { hemorrhagic areas }\end{array}$ \\
\hline $\begin{array}{l}\text { areas of MBT and/or mucinous } \\
\text { cystadenoma }\end{array}$ & $\begin{array}{l}\text { areas of MBT and/or mucinous cystadenoma less frequent, commonly } \\
\text { associated with high grade nuclear atypia }\end{array}$ & $\begin{array}{l}\text { nature of the content of } \\
\text { the cysts }\end{array}$ \\
\hline expansile invasion & infiltrative (destructive) invasion & pseudomyxoma ovarii \\
\hline complex papillary pattern & bilaterality & $\begin{array}{l}\text { cribriform, villous, or solid } \\
\text { growth }\end{array}$ \\
\hline size $>10 \mathrm{~cm}(>15 \mathrm{~cm})$ & hilar involvement & goblet cells \\
\hline associated teratoma or Brenner tumor & single cell invasion & tumor grade \\
\hline \multirow[t]{2}{*}{ microscopic cystic glands } & signet ring cells & $\begin{array}{l}\text { focal areas resembling } \\
\text { colonic carcinoma }\end{array}$ \\
\hline & vascular invasion & \\
\hline mural nodule & microscopic mucus on the surface & \\
\hline unilateral & pseudomyxoma peritonei & \\
\hline low stage & intraperitoneal spread & \\
\hline \multirow[t]{2}{*}{ low age } & colloid morphology & \\
\hline & established history of cancer & \\
\hline
\end{tabular}

$M B T$ mucinous borderline tumor

type of a mucin-producing fibrosarcoma. However, subsequent studies have shown that these tumors are indeed metastatic, most commonly with a primary source in gastric cancer and less often in colorectal cancer, with other locations being implicated only rarely [83]. Stromal reaction is a reactive process which often takes on a sarcomatoid appearance, and as such can cause difficulties in differential diagnosis. However, literature data on this tumor is severely influenced by inconsistencies in the approach to its classification. The term Krukenberg tumor is sometimes used for any adenocarcinoma metastasizing to the ovary, regardless of the presence of signet ring cells and stromal response. In some studies the tumors are even termed as Krukenberg tumors regardless of their primary source. Sometimes the term Krukenberg tumor is used only for gastrointestinal tract metastases. Nevertheless, we should be aware that signet ring cells may rarely occur even in primary ovarian mucinous carcinomas, so this feature is also not entirely specific for metastastic origin [84, 85]. However, signet ring cell histology compared to non-signet ring cell histology showed a specificity of $99.7 \%$ for indicating metastastic origin (with the sensitivity reaching only $12.0 \%$ ), with a positive predictive value for metastasis of $98.4 \%$ [62].

Another feature which is highly (although not entirely) specific for metastatic tumors is the presence of pseudomyxoma peritonei (PMP) [86]. The histogenesis of mucinous ovarian tumors is multifactorial, but current knowledge suggests that some tumors are of a teratomatous origin, whereas others may arise from mucinous metaplasia, probably in the form of Walthard's nests or in Brenner tumors [87]. Tumors arising in a teratoma, which represents $3-8 \%$ of ovarian mucinous tumors, show somewhat different morphological, immunohistochemical and other features, and represent a heterogeneous group of tumors [45]. They include tumors which in many respects mimic intestinal (appendicular) tumors, most likely arising from teratomatous lower intestinal tract tissue, and tumors which are close in morphology and immunophenotype to tumors from the upper gastrointestinal or pancreatobiliary tract. Moreover, a possible origin in sinonasal-type teratoma tissue has been suggested for some intestinal type adenocarcinomas, characterized by an immunophenotype indicative of upper gastrointestinal tract (with CK7 positivity and CK20 positivity or negativity) [45]. In contrast to tumors of non-teratomatous origin, which typically show diffuse CK7 expression and a variable CK20 expression, teratomatous tumors are more heterogeneous and include CK7 negative and CK20 positive cases (which is an immunophenotype typical for colorectal carcinoma).

Another difference from tumors of non-teratomatous origin is the frequent association with pseudomyxoma peritonei in teratoma-associated lesions. In a study of 42 teratoma-associated mucinous tumors, 10 were associated with PMP (1 MA, 6 MBT, and 3 MC) [43]. However, 4 cases classified as PMP in this study showed only the presence of acellular mucin, the other 3 contained epithelial structures with features of a low-grade mucinous tumor, and the last 3 displayed carcinomatous characteristics. Changes evaluated as pseudomyxoma ovarii were also present in 8 of these tumors. An 
appendectomy was performed in 7 patients, all of which showed no tumor structures in the appendix. Compared to PMP associated with a low grade mucinous tumor of the appendix (LAMN), the prognosis of PMP in teratoma-associated lesions appears to be better (except in cases of peritoneal carcinomatosis associated with $\mathrm{MC})$. However, the data is relatively limited in this respect. Macroscopically, the mucus of ovarian origin is much thinner compared to the thicker, jelly-like mucus of PMP associated with appendiceal tumors [88].

Generally, in the case of ovarian tumors showing morphology and immunophenotype characteristic for the lower gastrointestinal tract, one should consider the possibility of a minor teratomatous component which may have not been detected on sampling, and some authors recommend performing an extensive material re-examination, in addition to correlation with clinical data [45].

\section{Algorithmic approach to differential diagnosis of ovarian mucinous tumors}

We have found 11 studies focusing on the algorithmic approach to differential diagnosis between primary and metastatic mucinous ovarian cancer [3, 13, 16, 55-62]. Generally, the idea of an algorithmic approach is based on different gross features between primary and metastatic ovarian tumors, including especially the size and laterality. The most common approach is based on the assumption that a primary tumor is unilateral, in combination with a size criterion $(\geq 10 ; 12 ; 13$ or $15 \mathrm{~cm})$, and any and all other tumors are considered as metastatic. In some studies this algorithm is modified by excluding tumors with signet ring cell component, which are in most cases metastatic. Additionally, some algorithms also take into account other features, including the age of the patients and some immunohistochemical results, such as PAX8, DPEP1 (dipeptidase 1; a zincdependent metallopeptidase involved in glutathione metabolism which is commonly expressed in colorectal carcinoma), CK7 and CDX2 expression [13, 58]. Table 3 shows our summary of the algorithms used in 9 studies, in which the available data allowed for a comparison between the primary and metastatic cases (including the accuracy, sensitivity, specificity, negative predictive value (NPV), and positive predictive value (PPV)). Two studies were excluded from the analysis - one because it analyzed only metastatic cases, and the other one because it did not include the combination of size and laterality $[16,55]$. In certain aspects the results of all studies are similar, in that irrespectively of the algorithm used they generally show the same trend - if the criteria for primary (metastatic) tumor are stricter, then the increased specificity is associated with decreased sensitivity. The summary of the results from all the included studies showed the following: accuracy (mean 83.5\%, median
$83.8 \%$, range $71.3-96.1 \%$, SD 5.8); sensitivity for the identification of a primary tumor (mean $84.1 \%$, median $82.2 \%$, range $56.3-100 \%$, SD 14.3); specificity for the identification of a primary tumor (mean 82.8, median 81, range 72.2-94.7, SD 6.6).

In summary, algorithms by themselves are not sufficient for the definite distinction between primary and metastatic ovarian tumors, but they do provide important information which can be used in combination with microscopic features and immunohistochemical profile in order to classify most tumors with high accuracy. In one study, the suggested algorithm was intentionally optimized for high sensitivity for metastatic tumors, as the authors emphasized that a misdiagnosis of a metastatic tumor as a primary $\mathrm{MC}$ has greater consequences for the patient [62]. However, the achieved high sensitivity for mOC (90.1\%) was associated with low specificity (59.0\%). In another study, a combination of CDX2, CK7 and DPEP1 showed an accuracy of 97\% (56/58 tumors) for the detection of primary MC, and accuracy of $100 \%$ (16/16 tumors) for the detection of mCRC. However, the reported accuracy for metastases from the upper GIT reached only 56\% (9/16 cases) [58]. Interestingly, when the algorithm results were stratified according to the primary source of metastases, in one study the success ratio showed much better results for pancreatobiliary tract neoplasms than for colorectal carcinoma [57].

\section{Immunohistochemistry}

The results for all antibodies are summarized in Table 1 . The statistical significance of each antibody for the differential diagnosis is summarized in Table 4 . The results show that there are in fact several antibodies, which reached statistical significance when comparing primary mucinous tumors and metastatic / extraovarian tumors. However, statistical significance alone does not necessarily equate to practical usefulness. Generally, there is no single antibody upon which the decision concerning the primary source of the tumor may be based with certainty.

In the differential diagnosis between primary and metastatic ovarian mucinous tumors it is necessary to take into account the origin of the mucinous tumor because, as it has already been mentioned, some tumors arising in a teratoma may be indistinguishable from metastatic tumors on the IHC level $[43,45]$. In cases of other mucinous tumors, the use of IHC depends on the differential diagnosis in question.

In the differential diagnosis with metastases from the lower GIT (colorectal and appendiceal carcinoma) a combination of CK7, CK20, CDX2, SATB2, and PAX8 is often used. Especially for CK7 and CK20 it is appropriate to evaluate not only the presence of positivity, but also its extent and the relationship of mutual expression 
Table 3 Algorithmic approach to the differential diagnosis of ovarian mucinous tumors

\begin{tabular}{|c|c|c|c|c|c|c|c|c|}
\hline Study & $\begin{array}{l}\mathrm{N} \\
\text { primary }\end{array}$ & $\begin{array}{l}\mathrm{N} \\
\text { metastatic }\end{array}$ & Algorithm & $\begin{array}{l}\text { Accuracy } \\
\%\end{array}$ & $\begin{array}{l}\text { Sensitivity }{ }^{f} \\
\%\end{array}$ & $\begin{array}{l}\text { Specificity }{ }^{f} \\
\%\end{array}$ & PPV & NPV \\
\hline \multirow[t]{2}{*}{ Seidman et al. (Ref. [3]) } & 12 & 40 & $\geq 10 \mathrm{~cm}$, unilateral & 90.0 & 75.0 & 94.7 & 81.8 & 92.3 \\
\hline & & & $\geq 10 \mathrm{~cm}$, unilateral, excl. Signet ring cell & 83.0 & - & - & - & - \\
\hline \multirow{2}{*}{$\begin{array}{l}\text { Khunamorpong et al. } \\
\text { (Ref. [56]) }\end{array}$} & 16 & 52 & $\geq 10 \mathrm{~cm}$, unilateral, excl. Signet ring cell & 83.8 & 81.3 & 84.3 & 61.9 & 93.6 \\
\hline & & & $\geq 15 \mathrm{~cm}$, unilateral, excl. Signet ring cell & 83.8 & 56.3 & 92.3 & 69.2 & 87.3 \\
\hline \multirow{6}{*}{$\begin{array}{l}\text { Yemelyanova et al. } \\
\text { (Ref. [57]) }\end{array}$} & 52 & 142 & $\geq 10 \mathrm{~cm}$, unilateral & 83.5 & 100 & 77.5 & 61.9 & 100 \\
\hline & & & $\geq 10 \mathrm{~cm}$, unilateral, excl. Signet ring cell & 87.3 & 100 & 81 & 72.2 & 100 \\
\hline & & & $\geq 12 \mathrm{~cm}$, unilateral & 85.6 & 100 & 80.3 & 65 & 100 \\
\hline & & & $\geq 12 \mathrm{~cm}$, unilateral, excl. Signet ring cell & 83.2 & 100 & 75.7 & 65 & 100 \\
\hline & & & $\geq 13 \mathrm{~cm}$, unilateral & 86.1 & 98.1 & 81.7 & 66.2 & 99.1 \\
\hline & & & $\geq 13 \mathrm{~cm}$, unilateral, excl. Signet ring cell & 84.4 & 98.1 & 78.3 & 67.1 & 98.9 \\
\hline \multirow{2}{*}{$\begin{array}{l}\text { Okamoto et al. (Ref. } \\
\text { [58]) }\end{array}$} & $58^{c}$ & 36 & $\geq 10 \mathrm{~cm}$, unilateral & $71.3^{b}$ & - & - & - & - \\
\hline & & & DPEP1, CK7, CDX2, size ${ }^{d}$ & 93.3 & & & & \\
\hline \multirow[t]{5}{*}{ Jung et al. (Ref. [59]) } & 19 & 91 & $\geq 10 \mathrm{~cm}$, unilateral & 82.7 & 94.7 & 80.2 & 50 & 98.6 \\
\hline & & & $\geq 10 \mathrm{~cm}$, unilateral, excl. Signet ring cell & 80.6 & 94.7 & 77.7 & 51.4 & 98.3 \\
\hline & & & $\geq 13 \mathrm{~cm}$, unilateral & 87.3 & 78.9 & 89 & 60 & 95.3 \\
\hline & & & $\geq 13 \mathrm{~cm}$, unilateral, excl. Signet ring cell & 84.9 & 78.9 & 86.5 & 60 & 94.1 \\
\hline & & & $\geq 15 \mathrm{~cm}$, unilateral & 89.1 & 64.8 & 93.4 & 68.4 & 93.4 \\
\hline $\begin{array}{l}\text { Maeda-Taniguchi et al. } \\
\text { (Ref. 60]) }\end{array}$ & 51 & 22 & $\geq 10 \mathrm{~cm}$, unilateral & 75.3 & 70.6 & 86.4 & 92.3 & 55.9 \\
\hline \multirow[t]{2}{*}{ Hu et al. (Ref. [13]) } & 47 & 18 & $\begin{array}{l}\text { primary: } \geq 10 \mathrm{~cm} \text {, unilateral, PAX } 8+/- \\
\text { meta: PAX } 8 \text { - and bilateral (any size) or unilateral } \\
<10 \mathrm{~cm}\end{array}$ & 86.2 & 91.5 & 72.2 & 89.6 & 87 \\
\hline & & & $\geq 10 \mathrm{~cm}$, unilateral & 75.4 & - & - & - & - \\
\hline Hu et al. (Ref. [61]) & 61 & 68 & $\begin{array}{l}\text { primary: } \geq 13 \mathrm{~cm} \text { unless bilateral or has surface } \\
\text { nodules } \\
\text { meta: }<13 \mathrm{~cm} \text { unless unilateral }\end{array}$ & 96.1 & - & - & - & - \\
\hline \multirow[t]{3}{*}{ Simons et al. (Ref. [62]) } & 735 & 1018 & $\begin{array}{l}\text { algorithm based on histology (signet ring cells), } \\
\text { laterality, size and age } \mathrm{e}^{\mathrm{e}}\end{array}$ & 77.1 & 59 & 90.1 & 81.1 & 75.3 \\
\hline & & & $\geq 10 \mathrm{~cm}$, unilateral & 76.6 & 82.2 & 72.5 & 68.3 & 84.9 \\
\hline & & & $\geq 13 \mathrm{~cm}$, unilateral & 77.2 & 73.6 & 79.9 & 72.5 & 80.7 \\
\hline
\end{tabular}

a Excluding metastatic cases with endometrioid-like and signet ring cell features (only tumors with "mucinous" morphology left)

b Data from only 87 primary and metastatic cases, further details not available

c Incl. 13 cases on endocervical type MBT

${ }^{d}$ Criteria for size are not clear, for the details see ref. [58]

e For details see ref. [62]

${ }^{\mathrm{f}}$ Calculated for primary ovarian tumors

- data not available

of these 2 antibodies. Primary mucinous ovarian tumors express CK7 in about $90 \%$ of cases, and the expression is almost always diffuse (about $85 \%$ of tumors express CK7 in more than $50 \%$ of tumor cells, however, the criteria for diffuse expression vary among studies) [32, 33, 51, 89]. CK20 expression is also relatively common in primary ovarian mucinous tumors (about $65-70 \%$ of cases), but diffuse expression is found only in about $40 \%$ of cases. When evaluating the coordinate expression of CK7/CK20, regardless of its extent, primary ovarian mucinous tumors are positive for both markers in $67 \%$ of cases, CK7 positive / CK20 negative in $26 \%$ of cases, and CK7 negative / CK20 positive in only $7 \%$ of cases. However, primary mucinous tumors arising in a teratoma are CK7 negative / CK20 positive in $50 \%$ of cases [45]. CDX2 expression occurs in $49 \%$ of cases of primary tumors, but strong expression is observed in only $26 \%$ $[18,27,90,91]$. SATB2 is a marker which is significantly more specific for colorectal cancer than CDX2 [4-7, 10$12,92]$. In primary ovarian mucinous tumors SATB2 is 
Table 4 Statistical significance of immunohistochemical results between primary mucinous ovarian tumors and metastatic tumors

\begin{tabular}{|c|c|c|c|c|c|}
\hline & Appendix & Colorectum & Pancreas & Pancreatobiliary & Gastric \\
\hline SATB2 & $<0.001$ & $<0.001$ & 0.015 & 0.003 & 0.456 \\
\hline CDX2 & $<0.001$ & $<0.001$ & $<0.001$ & $<0.001$ & 0.076 \\
\hline CK7 & $<0.001$ & $<0.001$ & 0.094 & 0.028 & $<0.001$ \\
\hline CK20 & $<0.001$ & $<0.001$ & 0.031 & 0.001 & 0.904 \\
\hline B-catenin & NA & $<0.001$ & NA & 0.316 & 0.232 \\
\hline Villin & $<0.001$ & 0.039 & NA & NA & NA \\
\hline MUC1 & NA & 0.119 & $<0.001$ & $<0.001$ & 0.763 \\
\hline MUC2 & NA & $<0.001$ & $<0.001$ & $<0.001$ & 0.499 \\
\hline MUC5AC & NA & $<0.001$ & 0.277 & 0.013 & 0.276 \\
\hline MUC6 & NA & NA & 0.021 & 0.526 & 0.036 \\
\hline POF1B & NA & 0.126 & NA & 0.098 & 0.098 \\
\hline Ca19.9 & NA & 0.249 & 0.007 & 0.007 & NA \\
\hline DPC4 & 0.014 & $<0.001$ & $<0.001$ & $<0.001$ & 0.735 \\
\hline CEA & 0.002 & $<0.001$ & 0.316 & 0.316 & 0.224 \\
\hline PAX8 & $<0.001$ & $<0.001$ & 0.055 & 0.001 & $<0.001$ \\
\hline ER & NA & 0.032 & NA & 0.370 & 0.210 \\
\hline PR & NA & 0.583 & NA & NA & NA \\
\hline CA125 & 0.354 & 0.006 & NA & NA & 0.006 \\
\hline AMACR & NA & 0.025 & NA & NA & NA \\
\hline CK19 & NA & 0.170 & 0.076 & 0.076 & NA \\
\hline
\end{tabular}

$P$-values are based on Pearson Chi-square test or Fisher Exact test (italics). Significant $\mathrm{p}$-values are indicated in bold

Table $\mathbf{5}$ Immunohistochemical results of the coordinate expression

\begin{tabular}{|c|c|c|c|c|c|c|c|c|}
\hline & & Mucinous (all) (\%) & Mucinous teratoma (\%) & APE (\%) & CRC (\%) & Pancreas (\%) & Pancreatobiliary (\%) & $\overline{\text { Gastric (\%) }}$ \\
\hline \multirow[t]{3}{*}{ CDX2/CK20 } & $+/+$ & 50 & - & 90 & - & - & - & - \\
\hline & $-/+\mathrm{OR}+/-$ & 29.5 & - & 10 & - & - & - & - \\
\hline & $-/-$ & 20.5 & - & 0 & - & - & - & - \\
\hline \multirow[t]{3}{*}{ SATB2/CK20 } & $+/+$ & 0 & - & 80 & - & - & - & - \\
\hline & $-/+\mathrm{OR}+/-$ & 72.2 & - & 20 & - & - & - & - \\
\hline & $-/-$ & 27.8 & - & 0 & - & - & - & - \\
\hline \multirow[t]{4}{*}{ SATB2/PAX8 } & $+/+$ & 1.5 & - & - & - & - & - & - \\
\hline & $+/-$ & 10.2 & - & - & - & - & - & - \\
\hline & $-/+$ & 40 & - & - & - & - & - & - \\
\hline & $-/-$ & 48.3 & - & - & - & - & - & - \\
\hline \multirow[t]{4}{*}{ CK7/CK20 } & $+/+$ & 67.2 & 27 & 22.2 & 11.3 & 70.4 & 66.6 & 31.6 \\
\hline & $+/-$ & 26 & 16.2 & 0 & 3.2 & 25.9 & 28.2 & 21 \\
\hline & $-/+$ & 6.8 & 50 & 77.8 & 79 & 0 & 2.6 & 31.6 \\
\hline & $-/-$ & 0 & 6.8 & 0 & 6.5 & 3.7 & 2.6 & 15.8 \\
\hline \multirow[t]{4}{*}{$\mathrm{CK} 7 / \mathrm{CD} \times 2$} & $+/+$ & 37.2 & - & - & - & - & - & - \\
\hline & $+/-$ & 53.8 & - & - & - & - & - & - \\
\hline & $-/+$ & 9 & - & - & - & - & - & - \\
\hline & $-/-$ & 0 & - & - & - & - & - & - \\
\hline
\end{tabular}


expressed only in about $8 \%$ of cases. In contrast, PAX8 expression is reported in about $35 \%$ of primary cases, although it can be relatively weak and only focal. In comparison to primary mucinous ovarian tumors, colorectal and appendiceal carcinoma metastases show CK7 expression in 31 and $26 \%$ of cases respectively, although the expression is diffuse in only 6 and 13\% of cases. In contrast, CK20 is positive in 90 and $92 \%$ of cases, and almost always diffuse. CDX2 expression is positive in about $93 \%$ of colorectal and $97 \%$ of appendiceal cancers, and is almost always diffuse. SATB2 positivity is reported in $87 \%$ of appendiceal and $75 \%$ of colorectal tumors, and is almost always diffuse as well. According to our review, PAX8 is positive in about $5 \%$ of appendiceal cancers, while in colorectal cancer the expression of PAX8 has not been reported at all. Certain studies also evaluated the coordinate expression for some antibodies, which is an approach which seems to be more beneficial for the purposes of differential diagnosis. The most commonly used combination is CK7 and CK20, but combinations of other antibodies have been reported as well, including PAX8, CK7, CK20, CDX2 and SATB2. The results concerning the coordinate expression extracted from 10 studies are summarized in Table $5[5,9,16,20$, $22,38,43,45,51,93]$. However, with the exception of the CK7/CK20 combination, the data is rather limited. Briefly, the coordinate expression of CK7/CK20 in ovarian metastases is significantly different compared to primary mucinous tumors. The expression of both markers is reported in about $22 \%$ of appendiceal and $11 \%$ of colorectal cancers, and most these tumors (78 and 79\%) are CK7 negative / CK20 positive. According to our review, CK20 negative / CK7 positive staining pattern occurs in $0 \%$ of appendiceal tumors and about $3 \%$ of colorectal tumors. Negativity of both markers is reported in $0 \%$ of appendiceal and $6 \%$ of colorectal tumors. In summary, immunohistochemical examination can be helpful in the differential diagnosis between primary ovarian mucinous tumors and metastases from the "lower" GIT, but the use of a panel of antibodies and the correct interpretation of their results is crucial.

Metastases from the pancreatobiliary tract represent probably the most problematic category with regard to possible confusion with primary ovarian tumors $[8,17$, 66, 94]. Regarding the IHC examination, the antibodies listed in the differential diagnosis between primary ovarian mucinous tumors and metastases of the "lower" GIT are practically useless in the context of pancreatobiliary neoplasms. The expression of CK7 and CK20 is almost identical in both groups of tumors. Although the expression of CDX2 is slightly more common in primary ovarian mucinous tumors, in practice this difference is difficult to utilize $(49 \%$ positivity in primary ovarian tumors vs. $19 \%$ in pancreatic cancers and $31 \%$ in pancreatobiliary cancers). SATB2 expression is not reported in pancreatobiliary tumors; however, its expression in primary ovarian mucinous tumors is rare (7\%), which significantly limits its practical use. Of the other markers, the expression of PAX8, DPC4, and CK17 seems to be useful for the purposes of differential diagnosis. PAX8 is reported to be positive in $36 \%$ of primary ovarian mucinous tumors and in $4 \%$ of pancreatobiliary tumors. However, the sensitivity of this marker is low. A loss of DPC4 (SMAD4) expression occurs in $53 \%$ of pancreatic and only about $5-10 \%$ of primary ovarian mucinous tumors $[28,36,37,95]$. According to the literature, cytokeratin 17 seems to be negative in ovarian mucinous tumors and positive in $27-83 \%$ of metastatic pancreatic carcinomas, but the data is very limited $[94,96]$.

The most problematic (on the IHC level) is the distinction between primary ovarian mucinous tumor and gastric adenocarcinoma metastasis [75, 97, 98]. Morphologically, some of the metastases have a signet ring cell component, or consist only of these elements, which is a feature strongly suggestive against the diagnosis of a primary ovarian tumor. However, it is very complicated to make the distinction between primary and metastatic tumors based on IHC results. The expression of CK7, CK20, CDX2 and SATB2 is very similar in both groups and therefore these markers cannot be used. Practically useful antibodies are mainly represented by PAX8 (positive in $35 \%$ of primary mucinous tumors vs. $0 \%$ of gastric cancers) and CA125 (positive in $24 \%$ of primary mucinous tumors vs. $0 \%$ of gastric cancers). However, these antibodies are only significant when the staining result is positive and their sensitivity is low. A minority of primary ovarian mucinous tumors $(<10 \%)$ may also weakly express ER and PR. The expression of ER/PR is not reported in gastric cancer, but again it is a marker with very low sensitivity.

\section{Incidence of metastases and their primary source}

The frequency of ovarian metastases from the GIT may vary, but according to the literature ovarian metastases occur during the course of the disease in $2 \%$ of patients with colorectal cancer and $2.9 \%$ of patients with gastric cancer [69, 75, 78, 97, 99-103]. Concerning ovarian metastases, we have analyzed the data from 13 studies, which were used to mine the information on primary source $[3,28,46,60,80,104-111]$. Moreover, 5 of these studies also provided data concerning the percentage of metastatic ovarian cancer from all (primary and metastatic) ovarian tumors. Based on these 5 studies, we were able to determine that out of the 14,060 cases of ovarian cancers 656 cases $(4.7 \%)$ were metastases. Based on all of the 13 studies, the most common primary source was colorectal carcinoma (32\%), followed by breast carcinoma (15.4\%), endometrial carcinoma (12.9\%), gastric 
carcinoma (9.2\%), appendiceal carcinoma (6.7\%), uterine cervix carcinoma (2.4\%), pancreatic carcinoma (2.2\%), small intestine carcinoma (1.6\%), and carcinoma of the gallbladder and biliary tract (1.5\%). Other tumors such as lung carcinoma, skin tumors, kidney cancer, and esophageal carcinoma each accounted for less than $1 \%$. For the entire group of metastatic tumors the primary source was unknown in $12.2 \%$.

\section{Discussion}

Metastatic ovarian tumors are common, however, according to published literature their frequency covers a wide range and represents $5-30 \%$ of all ovarian carcinomas $[29,46,109,112]$. According to our review, 4.7\% of ovarian cancers were metastatic. Most of the ovarian metastases have a primary source in GIT tumors, which accounted for $53.2 \%$ of tumors according to our review. The distinction between primary ovarian MC and ovarian metastasis from another primary source is important and has a direct influence on patient's treatment and prognosis. Although this topic has been given relatively a lot of attention in the literature, the historical data is equivocal due to the fact that some tumors previously classified as primary $\mathrm{MC}$ were in fact metastases [3]. Today, the knowledge that certain metastatic tumors can mimic primary mucinous ovarian tumors is well recognized [81, 82]. The situation is also complicated by the fact that a subset of ovarian metastases represents the first manifestation of a hitherto unrecognized extraovarian disease. Despite the increasing knowledge on this issue, including advancements in the array of methodological options, currently there still are no methods or algorithms which would allow us to distinguish between primary and metastatic tumors with certainty and this remains problematic area as is acknowledged in the new 5th edition of WHO Classification of Female genital organs tumors as well [113]. For a proportion of tumors the primary source of the tumor remains unclear even after exhaustive comprehensive examinations. These cases must be addressed within multidisciplinary teams, but in rare cases, ambiguities persist even after a comprehensive clinico-pathological evaluation. The metastatic nature of a certain ovarian tumor may in some cases become apparent only after several months, due to the manifestation of the previously occult, unrecognized extraovarian tumor [114].

Another approach which can be theoretically helpful in the differential diagnosis of ovarian mucinous tumors is their molecular characterization. However, according to current knowledge the aberration occurring in ovarian mucinous tumors are not specific, which prevents the use of molecular pathology in this setting. Briefly, the most common aberrations occurring in primary mucinous ovarian carcinoma are mutations of KRAS $(\approx 55 \%)$,
CDKN2A $(\approx 55 \%$, including deletions), TP53 $(\approx 52 \%)$, ARID1A $(\approx 10 \%), B R A F(\approx 8 \%)$, and amplification of HER2 $(\approx 28 \%)$ [115-121]. The aberrations occurring in MBT are similar, with mutations of KRAS ( $\approx 55 \%)$, CDKN2A ( $\approx 44 \%$, including deletions), TP53 ( $\approx 12 \%), B R A F$ $(\approx 11 \%)$, and amplification of HER2 $(\approx 10 \%)$ [122-126].

The summary of current knowledge shows that most tumors can be reliably classified with respect to the primary source based on the morphological criteria, which include the assessment of macroscopic features, microscopic findings, and immunohistochemical profile of the tumor. However, a minority of tumors, especially from the upper GIT, pancreas and biliary tree, remain problematic in this context $[55,66,94]$. The problem is especially caused by the fact that the morphologic features and immunophenotype of primary mucinous ovarian tumors are not specific, and there are overlapping features with metastases. Although certain features are more common in metastatic tumors (such as surface involvement, nodular growth, hilar involvement and the presence of signet ring cells), they are not specific [17]. Moreover, some metastatic tumors can demonstrate features more common for primary tumors, such as a large size, unilaterality, absence of surface involvement, and areas of benign or borderline appearance (which can rarely be the only morphological pattern). The role of immunohistochemistry in the distinction between primary and secondary ovarian mucinous tumors may be helpful, but we should be aware of its benefits and limitations. First of all there is no single antibody which can differentiate between these tumors with absolute certainty. Immunohistochemical antibodies should be used as a part of a panel, which may be composed as a general one, or be more targeted to a particular possible primary source. Moreover, we should take into account the fact that primary mucinous ovarian tumors which are of a teratomatous origin may share not only the morphology, but also the IHC profile with their intestinal or upper GIT counterpart. It is also important to be aware of coordinate expression, which may be more helpful than isolated assessment of each antibody. Various combinations of PAX8, CK7, CK20, CDX2 and SATB2 have been used with varying success $[5,9,16,20,22,38,43$, $45,51,93]$. However, with the exception of the CK7/ CK20 combination, the data on their usefulness is rather limited. Based on our review, the immunohistochemistry may be helpful, but contrary to other tumor types, in the distinction between primary mucinous ovarian tumors vs. ovarian metastases from the GIT, pancreas and biliary tree, the role of IHC is rather limited. In general, we should keep in mind the overlapping IHC results between primary and secondary tumors originating from GIT. Also, certain antibodies (such as DPC4) lack sensitivity despite having high specificity. 
Additionally, in the differential diagnosis between primary mucinous ovarian tumors and GIT metastasis we should also be aware of the possibility of metastases from cervical adenocarcinoma, which may have morphological features resembling both primary ovarian tumors and GIT metastases [63, 127]. In the case of HPVassociated adenocarcinomas, the best marker for differential diagnosis seems to be p16 [128-130]. Diffuse expression of p16 (>90\% of tumor cells) is very rare in primary mucinous tumors - the largest study focusing on this issue reported diffuse p16 positivity in $5.7 \%$ of primary ovarian mucinous carcinomas [131]. In another study the sensitivity of p16 positivity for ovarian metastases of cervical adenocarcinoma reached $100 \%$, with specificity of $98 \%$ [128]. However, literary data concerning immunohistochemical profile of HPV-independent related cervical adenocarcinomas of gastric type are limited. According to the largest study focusing on this topic, gastric type cervical adenocarcinomas are positive for CK7 in 100\% of cases, CK20 in 49\%, CDX2 in 51\%, Ca125 in $80 \%$, PAX8 in $68 \%$, ER in $6 \%$, PR in $9 \%$ and MUC6 in $81 \%$ of cases [132]. According to these results, immunohistochemistry is not very helpful in the differential diagnosis of HPV-independent cervical adenocarcinoma and close clinico-pathological correlation is essential.

The role of a pathologist is crucial not only in determining the final diagnosis (with the use of ancillary methods and clinico-pathological correlations), but also in the perioperative (frozen section) examination. In this setting, the distinction between primary and metastatic tumor can fundamentally modify the surgical procedure, but is usually complicated by limited sampling and the impossibility of utilizing immunohistochemical examinations. In this situation, the benefit of an algorithmic approach combining the macroscopic characteristics of the tumor with histological features can be significant. However, the available algorithms based on the evaluation of macroscopic characteristics of tumors cannot distinguish between primary and metastatic tumors with certainty, despite having a relatively high overall accuracy, sensitivity and specificity. Complementary to the macroscopic and histologic features, it has been shown that the age of the patient represents another important factor possibly playing a role in the differential diagnosis of primary vs. metastatic tumors. In one study from 2011, only $9.1 \%$ $(2 / 22)$ of metastases occur in females younger than 50 years [60]. In the group of primary tumors, however, $49 \%$ of patients were younger than 50 years. The factor of age has even been incorporated into the diagnostic algorithm of one recent study [62].

In conclusion, the distinction between primary and secondary ovarian mucinous tumors can be straightforward, but there are still cases in which achieving the correct diagnosis may be complicated. This includes especially two situations which can seriously influence the correct treatment of the patient. In one of them, ovarian metastasis may be misdiagnosed as a primary ovarian tumor due to the pathological features which may simulate primary ovarian tumor. In most such cases the clinical examination reveals the primary tumor in another location. However, in rare cases the primary tumor can be undetectable at the time of diagnosis and will only become clinically apparent later during the course of the disease. This is the reason why each mucinous ovarian tumor, especially carcinoma, should be regarded with caution and thorough clinical examination of the patient with close follow-up is desirable. In the second situation, ovarian tumor with pathological features of metastasis may be the primary manifestation of the disease, which is at the time of diagnosis not detectable despite extensive examination of the patient. In this situation, the pathologist has to pass the information about equivocal features of ovarian tumor suggestive of metastatic origin to the clinicians even in the absence of clinically detectable another potentially primary tumor. The primary tumor in these cases will probably manifest itself later during the disease and a close follow-up of the patient is necessary. According to the current knowledge, the most reliable approach to the diagnosis of ovarian mucinous tumors combines macroscopic, microscopic, and immunohistochemical assessment combined with a close clinico-pathological correlation. However, we should be aware that despite all the effort, there are still rare cases in which the diagnosis cannot be achieved with certainty.

\section{Abbreviations}

GIT: Gastrointestinal tract; IHC: Immunohistochemical; LAMN: Low grade appendiceal mucinous neoplasm; MA: Mucinous cystadenoma; MBT: Mucinous borderline tumor; MC: Mucinous ovarian carcinoma; MeSH: Medical Subject Headings; NPV: Negative predictive value; PMP: Pseudomyxoma peritone; PPV: Positive predictive value; SEER: Surveillance Epidemiologic and End Results

\footnotetext{
Authors' contributions

All authors have made substantial contributions: conception and design (PD, $N S)$, acquisition of data (PD, BN, KN, MB), analysis and interpretation of data $(P D, N S, B N, K N, M B, I S)$. PD has been involved in the drafting of the manuscript, all other authors have been involved in revising it critically. All authors agree to be accountable for all aspects of the work in ensuring that questions related to the accuracy or integrity of any part of the work are appropriately investigated and resolved. All authors have given final approval of the version to be published.
}

\section{Funding}

This work was supported by Ministry of Health, Czech Republic (Research project AZV NV19-03-00007 and Conceptual development of research organization 64165, General University Hospital in Prague), by Charles University (Project Progress Q28/LF1, UNCE204065 and SW260367), and by the European Regional Development Fund (CZ.02.1.01/0.0/0.0/18_046/ 0015959; BBMRI_CZ LM2018125). 


\section{Availability of data and materials}

The datasets generated during the current study are available from the corresponding author on reasonable request.

\section{Declarations}

\section{Ethics approval and consent to participate}

Not applicable.

\section{Consent for publication}

Not applicable.

\section{Competing interests}

The authors declare that they have no competing interests.

\section{Author details}

${ }^{1}$ Institute of Pathology, First Faculty of Medicine, Charles University and General University Hospital in Prague, Studničkova 2, 12800 Prague 2, Czech Republic. ${ }^{2}$ Department of Cellular Pathology, Barts Health NHS Trust, Queen Mary University of London, London, UK. ${ }^{3}$ Blizard Institute of Core Pathology, Queen Mary University of London, London, UK

Received: 20 January 2021 Accepted: 21 February 2021

Published online: 11 March 2021

\section{References}

1. Platz CE, Benda JA. Female genital tract cancer. Cancer. 1995;75(1 Suppl): 270-94.

2. Mink PJ, Sherman ME, Devesa SS. Incidence patterns of invasive and borderline ovarian tumors among white women and black women in the United States. Results from the SEER program, 1978-1998. Cancer. 2002; 95(11):2380-9.

3. Seidman JD, Kurman RJ, Ronnett BM. Primary and metastatic mucinous adenocarcinomas in the ovaries: incidence in routine practice with a new approach to improve intraoperative diagnosis. Am J Surg Pathol. 2003;27(7): 985-93.

4. Liu F, Gao Z, Shen D, Zhao H, Wang C, Ye Y, et al. Significance of SATB2 expression in colon cancer and its differential diagnosis in digestive tract adenocarcinoma and ovarian primary and metastatic carcinoma. Pathol Res Pract. 2019;215(7):152430

5. Meagher NS, Wang L, Rambau PF, Intermaggio MP, Huntsman DG, Wilkens $L R$, et al. A combination of the immunohistochemical markers CK7 and SATB2 is highly sensitive and specific for distinguishing primary ovarian mucinous tumors from colorectal and appendiceal metastases. Mod Pathol. 2019;32(12):1834-46

6. Aldaoud N, Erashdi M, AlKhatib S, Abdo N, Al-Mohtaseb A, Graboski-Bauer A. The utility of PAX8 and SATB2 immunohistochemical stains in distinguishing ovarian mucinous neoplasms from colonic and appendiceal mucinous neoplasm. BMC Res Notes. 2019;12(1):770.

7. Schmoeckel E, Kirchner T, Mayr D. SATB2 is a supportive marker for the differentiation of a primary mucinous tumor of the ovary and an ovarian metastasis of a low-grade appendiceal mucinous neoplasm (LAMN): a series of seven cases. Pathol Res Pract. 2018;214(3):426-30.

8. Park CK, Kim HS. Clinicopathological characteristics of ovarian metastasis from colorectal and Pancreatobiliary carcinomas mimicking primary ovarian mucinous tumor. Anticancer Res. 2018;38(9):5465-73.

9. Li Z, Roth R, Rock JB, Lehman A, Marsh WL, Suarez A, et al. Dual immunostain with SATB2 and CK20 differentiates Appendiceal mucinous neoplasms from ovarian mucinous neoplasms. Am J Clin Pathol. 2017; 147(5):484-91

10. Strickland S, Wasserman JK, Giassi A, Djordjevic B, Parra-Herran C. Immunohistochemistry in the diagnosis of mucinous neoplasms involving the ovary: the added value of SATB2 and biomarker discovery through protein expression database mining. Int J Gynecol Pathol. 2016; 35(3):191-208.

11. Moh M, Krings G, Ates D, Aysal A, Kim GE, Rabban JT. SATB2 expression distinguishes ovarian metastases of colorectal and Appendiceal origin from primary ovarian tumors of mucinous or Endometrioid type. Am J Surg Pathol. 2016;40(3):419-32.

12. Perez Montiel D, Arispe Angulo K, Cantú-de León D, Bornstein Quevedo L, Chanona Vilchis J, Herrera ML. The value of SATB2 in the differential diagnosis of intestinal-type mucinous tumors of the ovary: primary vs metastatic. Ann Diagn Pathol. 2015;19(4):249-52.

13. Hu A, Li H, Zhang L, Ren C, Wang Y, Liu Y, et al. Differentiating primary and extragenital metastatic mucinous ovarian tumours: an algorithm combining PAX8 with tumour size and laterality. J Clin Pathol. 2015;68(7):522-8.

14. Wang J, El-Bahrawy MA. Expression profile of mucins in ovarian mucinous tumors: distinguishing primary ovarian from metastatic tumors. Int J Gynecol Pathol. 2014;33(2):166-75.

15. Almeida BG, Bacchi CE, Carvalho JP, Ferreira CR, Carvalho FM. The role of intratumoral lymphovascular density in distinguishing primary from secondary mucinous ovarian tumors. Clinics (Sao Paulo). 2014;69(10):660-5.

16. Pinto PB, Derchain SF, Andrade LA. Metastatic mucinous carcinomas in the ovary: a practical approach to diagnosis related to gross aspects and to immunohistochemical evaluation. Int J Gynecol Pathol. 2012;31(4):313-8.

17. Meriden Z, Yemelyanova AV, Vang R, Ronnett BM. Ovarian metastases of pancreaticobiliary tract adenocarcinomas: analysis of 35 cases, with emphasis on the ability of metastases to simulate primary ovarian mucinous tumors. Am J Surg Pathol. 2011;35(2):276-88.

18. Shin JH, Bae JH, Lee A, Jung CK, Yim HW, Park JS, et al. CK7, CK20, CDX2 and MUC2 Immunohistochemical staining used to distinguish metastatic colorectal carcinoma involving ovary from primary ovarian mucinous adenocarcinoma. Jpn J Clin Oncol. 2010;40(3):208-13.

19. Silverman JF, Zhu B, Liu Y, Lin X. Distinctive immunohistochemical profile of mucinous cystic neoplasms of pancreas, ovary and lung. Histol Histopathol. 2009;24(1):77-82.

20. Khunamornpong S, Lerwill MF, Siriaunkgul S, Suprasert P, Pojchamarnwiputh $\mathrm{S}$, Chiangmai WN, et al. Carcinoma of extrahepatic bile ducts and gallbladder metastatic to the ovary: a report of 16 cases. Int J Gynecol Pathol. 2008;27(3):366-79.

21. Zapata M, Cohen C, Siddiqui MT. Immunohistochemical expression of SMAD4, CK19, and CA19-9 in fine needle aspiration samples of pancreatic adenocarcinoma: utility and potential role. Cytojournal. 2007;4:13.

22. Vang R, Gown AM, Wu LS, Barry TS, Wheeler DT, Yemelyanova A, et al. Immunohistochemical expression of CDX2 in primary ovarian mucinous tumors and metastatic mucinous carcinomas involving the ovary: comparison with CK20 and correlation with coordinate expression of CK7. Mod Pathol. 2006;19(11):1421-8.

23. Lewis MR, Deavers MT, Silva EG, Malpica A. Ovarian involvement by metastatic colorectal adenocarcinoma: still a diagnostic challenge. Am J Surg Pathol. 2006;30(2):177-84.

24. Logani S, Oliva E, Arnell PM, Amin MB, Young RH. Use of novel immunohistochemical markers expressed in colonic adenocarcinoma to distinguish primary ovarian tumors from metastatic colorectal carcinoma. Mod Pathol. 2005;18(1):19-25.

25. Kim MJ. The usefulness of CDX-2 for differentiating primary and metastatic ovarian carcinoma: an immunohistochemical study using a tissue microarray. J Korean Med Sci. 2005;20(4):643-8.

26. Chou YY, Jeng YM, Kao HL, Chen T, Mao TL, Lin MC. Differentiation of ovarian mucinous carcinoma and metastatic colorectal adenocarcinoma by immunostaining with beta-catenin. Histopathology. 2003;43(2):151-6.

27. Fraggetta F, Pelosi G, Cafici A, Scollo P, Nuciforo P, Viale G. CDX2 immunoreactivity in primary and metastatic ovarian mucinous tumours. Virchows Arch. 2003;443(6):782-6.

28. Ji H, Isacson C, Seidman JD, Kurman RJ, Ronnett BM. Cytokeratins 7 and 20, Dpc4, and MUC5AC in the distinction of metastatic mucinous carcinomas in the ovary from primary ovarian mucinous tumors: Dpc4 assists in identifying metastatic pancreatic carcinomas. Int J Gynecol Pathol. 2002; 21(4):391-400.

29. Dionigi A, Facco C, Tibiletti MG, Bernasconi B, Riva C, Capella C. Ovarian metastases from colorectal carcinoma. Clinicopathologic profile, immunophenotype, and karyotype analysis. Am J Clin Pathol. 2000;114(1): $111-22$.

30. Lagendijk JH, Mullink $H$, van Diest PJ, Meijer GA, Meijer CJ. Immunohistochemical differentiation between primary adenocarcinomas of the ovary and ovarian metastases of colonic and breast origin. Comparison between a statistical and an intuitive approach. J Clin Pathol. 1999;52(4): 283-90

31. Wauters CC, Smedts F, Gerrits LG, Bosman FT, Ramaekers FC. Keratins 7 and 20 as diagnostic markers of carcinomas metastatic to the ovary. Hum Pathol. 1995:26(8):852-5. 
32. Ueda G, Sawada M, Ogawa H, Tanizawa O, Tsujimoto M. Immunohistochemical study of cytokeratin 7 for the differential diagnosis of adenocarcinomas in the ovary. Gynecol Oncol. 1993;51(2):219-23.

33. Moll R, Löwe A, Laufer J, Franke WW. Cytokeratin 20 in human carcinomas, A new histodiagnostic marker detected by monoclonal antibodies. Am J Pathol. 1992;140(2):427-47.

34. Daya D, Nazerali L, Frank GL. Metastatic ovarian carcinoma of large intestinal origin simulating primary ovarian carcinoma. A clinicopathologic study of 25 cases. Am J Clin Pathol. 1992;97(6):751-8.

35. Nonaka D, Chiriboga L, Soslow RA. Expression of pax8 as a useful marker in distinguishing ovarian carcinomas from mammary carcinomas. Am J Surg Pathol. 2008;32(10):1566-71.

36. Ritterhouse LL, Wu EY, Kim WG, Dillon DA, Hirsch MS, Sholl LM, et al. Loss of SMAD4 protein expression in gastrointestinal and extra-gastrointestinal carcinomas. Histopathology. 2019;75(4):546-51.

37. Alghamdi S, Alghaashamy K, Pinto A. Expression of SMAD4 is retained in Most gynecologic tumors with mucinous differentiation. Int J Gynecol Pathol. 2019.

38. Bassiouny D, Ismiil N, Dubé V, Han G, Cesari M, Lu Fl, et al. Comprehensive Clinicopathologic and updated Immunohistochemical characterization of primary ovarian mucinous carcinoma. Int J Surg Pathol. 2018;26(4):306-17.

39. Zhu Q, Qu Y, Zhang Q, Lu L, Weng W, Zhang H, et al. IMP3 is upregulated in primary ovarian mucinous carcinoma and promotes tumor progression. Am J Transl Res. 2017;9(7):3387-98.

40. Wang J, El-Bahrawy M. Expression profile of mucins (MUC1, MUC2, MUC5AC, and MUC6) in ovarian mucinous tumours: changes in expression from benign to malignant tumours. Histopathology. 2015;66(4):529-35.

41. Halimi SA, Maeda D, Shinozaki-Ushiku A, Koso T, Matsusaka K, Tanaka M, et al. Claudin-18 overexpression in intestinal-type mucinous borderline tumour of the ovary. Histopathology. 2013;63(4):534-44.

42. Tabrizi AD, Kalloger SE, Kobel M, Cipollone J, Roskelley CD, Mehl E, et al. Primary ovarian mucinous carcinoma of intestinal type: significance of pattern of invasion and immunohistochemical expression profile in a series of 31 cases. Int J Gynecol Pathol. 2010;29(2):99-107.

43. McKenney JK, Soslow RA, Longacre TA. Ovarian mature teratomas with mucinous epithelial neoplasms: morphologic heterogeneity and association with pseudomyxoma peritonei. Am J Surg Pathol. 2008; 32(5):645-55

44. Lin X, Lindner JL, Silverman JF, Liu Y. Intestinal type and endocervical-like ovarian mucinous neoplasms are immunophenotypically distinct entities. Appl Immunohistochem Mol Morphol. 2008;16(5):453-8.

45. Vang R, Gown AM, Zhao C, Barry TS, Isacson C, Richardson MS, et al. Ovarian mucinous tumors associated with mature cystic teratomas: morphologic and immunohistochemical analysis identifies a subset of potential teratomatous origin that shares features of lower gastrointestinal tract mucinous tumors more commonly encountered as secondary tumors in the ovary. Am J Surg Pathol. 2007;31(6):854-69.

46. Alvarado-Cabrero I, Rodríguez-Gómez A, Castelan-Pedraza J, Valencia-Cedillo R. Metastatic ovarian tumors: a clinicopathologic study of 150 cases. Anal Quant Cytopathol Histpathol. 2013;35(5):241-8

47. Acs G, Pasha T, Zhang PJ. WT1 is differentially expressed in serous, endometrioid, clear cell, and mucinous carcinomas of the peritoneum, fallopian tube, ovary, and endometrium. Int J Gynecol Pathol. 2004; 23(2):110-8

48. Neunteufel W, Breitenecker G. Tissue expression of CA 125 in benign and malignant lesions of ovary and fallopian tube: a comparison with CA 19-9 and CEA. Gynecol Oncol. 1989;32(3):297-302.

49. Viale G, Gambacorta M, Dell'Orto P, Coggi G. Coexpression of cytokeratins and vimentin in common epithelial tumours of the ovary: an immunocytochemical study of eighty-three cases. Virchows Arch A Pathol Anat Histopathol. 1988;413(2):91-101

50. Dabbs DJ, Geisinger KR. Common epithelial ovarian tumors. Immunohistochemical intermediate filament profiles. Cancer. 1988;62(2): 368-74

51. Chu P, Wu E, Weiss LM. Cytokeratin 7 and cytokeratin 20 expression in epithelial neoplasms: a survey of 435 cases. Mod Pathol. 2000;13(9):962-72

52. Chu PG, Schwarz RE, Lau SK, Yen Y, Weiss LM. Immunohistochemical staining in the diagnosis of pancreatobiliary and ampulla of Vater adenocarcinoma: application of CDX2, CK17, MUC1, and MUC2. Am J Surg Pathol. 2005:29(3):359-67.
53. Bewick V, Cheek L, Ball J. Statistics review 8: qualitative data - tests of association. Crit Care. 2004:8(1):46-53.

54. McHugh ML. The chi-square test of independence. Biochem Med (Zagreb). 2013;23(2):143-9.

55. Lee $\mathrm{KR}$, Young $\mathrm{RH}$. The distinction between primary and metastatic mucinous carcinomas of the ovary: gross and histologic findings in 50 cases. Am J Surg Pathol. 2003;27(3):281-92.

56. Khunamornpong S, Suprasert P, Pojchamarnwiputh S, Na Chiangmai W, Settakorn J, Siriaunkgul S. Primary and metastatic mucinous adenocarcinomas of the ovary: evaluation of the diagnostic approach using tumor size and laterality. Gynecol Oncol. 2006;101(1):152-7.

57. Yemelyanova AV, Vang R, Judson K, Wu LS, Ronnett BM. Distinction of primary and metastatic mucinous tumors involving the ovary: analysis of size and laterality data by primary site with reevaluation of an algorithm for tumor classification. Am J Surg Pathol. 2008;32(1):128-38.

58. Okamoto T, Matsumura N, Mandai M, Oura T, Yamanishi Y, Horiuchi A, et al. Distinguishing primary from secondary mucinous ovarian tumors: an algorithm using the novel marker DPEP1. Mod Pathol. 2011;24(2):267-76.

59. Jung ES, Bae JH, Lee A, Choi YJ, Park JS, Lee KY. Mucinous adenocarcinoma involving the ovary: comparative evaluation of the classification algorithms using tumor size and laterality. J Korean Med Sci. 2010;25(2):220-5.

60. Maeda-Taniguchi M, Ueda Y, Miyake T, Miyatake T, Kimura T, Yoshino K, et al. Metastatic mucinous adenocarcinoma of the ovary is characterized by advanced patient age, small tumor size, and elevated serum CA125. Gynecol Obstet Investig. 2011;72(3):196-202.

61. Hu J, Khalifa RD, Roma AA, Fadare $\mathrm{O}$. The pathologic distinction of primary and metastatic mucinous tumors involving the ovary: a re-evaluation of algorithms based on gross features. Ann Diagn Pathol. 2018;37:1-6.

62. Simons M, Bolhuis T, De Haan AF, Bruggink AH, Bulten J, Massuger LF, et al. A novel algorithm for better distinction of primary mucinous ovarian carcinomas and mucinous carcinomas metastatic to the ovary. Virchows Arch. 2019:474(3):289-96.

63. Casey $\mathrm{L}$, Singh N. Metastases to the ovary arising from endometrial, cervical and fallopian tube cancer: recent advances. Histopathology. 2020;76(1):37-51

64. Leen SL, Singh N. Pathology of primary and metastatic mucinous ovarian neoplasms. J Clin Pathol. 2012;65(7):591-5.

65. Yoshida H, Tanaka H, Tsukada T, Abeto N, Kobayashi-Kato M, Tanase Y, et al. Gross mucinous multinodular appearance aids in the identification of ovarian metastases in low-grade appendiceal mucinous neoplasms during intraoperative consultation. Ann Diagn Pathol. 2021;50:151641.

66. Young $\mathrm{RH}$, Hart WR. Metastases from carcinomas of the pancreas simulating primary mucinous tumors of the ovary. A report of seven cases. Am J Surg Pathol. 1989;13(9):748-56.

67. Young RH, Scully RE. Ovarian metastases from carcinoma of the gallbladder and extrahepatic bile ducts simulating primary tumors of the ovary. A report of six cases. Int J Gynecol Pathol. 1990:9(1):60-72.

68. Boger-Megiddo I, Weiss NS. Histologic subtypes and laterality of primary epithelial ovarian tumors. Gynecol Oncol. 2005;97(1):80-3.

69. Kim DD, Park IJ, Kim HC, Yu CS, Kim JC. Ovarian metastases from colorectal cancer: a clinicopathological analysis of 103 patients. Color Dis. 2009;11(1):32-8.

70. Lash RH, Hart WR. Intestinal adenocarcinomas metastatic to the ovaries. A clinicopathologic evaluation of 22 cases. Am J Surg Pathol. 1987; 11(2):114-21.

71. Ursem C, Zhou M, Paciorek A, Atreya CE, Ko AH, Venook A, et al. Clinicopathologic Characteristics and Impact of Oophorectomy for Ovarian Metastases from Colorectal Cancer. Oncologist. 2020.

72. Ma F, Li Y, Li W, Kang W, Liu H, Ma S, et al. Metastasectomy improves the survival of gastric Cancer patients with Krukenberg tumors: a retrospective analysis of 182 patients. Cancer Manag Res. 2019;11:10573-80.

73. Lobo J, Machado B, Vieira R, Bartosch C. The challenge of diagnosing a malignancy metastatic to the ovary: clinicopathological characteristics vary and morphology can be different from that of the corresponding primary tumor. Virchows Arch. 2017:470(1):69-80.

74. Jeung YJ, Ok HJ, Kim WG, Kim SH, Lee TH. Krukenberg tumors of gastric origin versus colorectal origin. Obstet Gynecol Sci. 2015;58(1):32-9.

75. Feng Q, Pei W, Zheng ZX, Bi JJ, Yuan XH. Clinicopathologic characteristics and prognostic factors of 63 gastric cancer patients with metachronous ovarian metastasis. Cancer Biol Med. 2013:10(2):86-91. 
76. Lu LC, Shao YY, Hsu CH, Hsu C, Cheng WF, Lin YL, et al. Metastasectomy of Krukenberg tumors may be associated with survival benefits in patients with metastatic gastric cancer. Anticancer Res. 2012;32(8):3397-401.

77. Qiu L, Yang T, Shan XH, Hu MB, Li Y. Metastatic factors for Krukenberg tumor: a clinical study on 102 cases. Med Oncol. 2011;28(4):1514-9.

78. Tan KL, Tan WS, Lim JF, Eu KW. Krukenberg tumors of colorectal origin: a dismal outcome--experience of a tertiary center. Int J Color Dis. 2010;25(2): 233-8.

79. Mondal SK, Banyopadhyay R, Nag DR, Roychowdhury S, Mondal PK, Sinha SK. Histologic pattern, bilaterality and clinical evaluation of 957 ovarian neoplasms: a 10-year study in a tertiary hospital of eastern India. J Cancer Res Ther. 2011;7(4):433-7

80. Khunamornpong S, Suprasert P, Chiangmai WN, Siriaunkgul S. Metastatic tumors to the ovaries: a study of 170 cases in northern Thailand. Int J Gynecol Cancer. 2006;16(Suppl 1):132-8.

81. Young RH. From krukenberg to today: the ever present problems posed by metastatic tumors in the ovary: part I. historical perspective, general principles, mucinous tumors including the krukenberg tumor. Adv Anat Pathol. 2006;13(5):205-27.

82. Young RH. From Krukenberg to today: the ever present problems posed by metastatic tumors in the ovary. Part II Adv Anat Pathol. 2007:14(3):149-77.

83. Holtz F, Hart WR. Krukenberg tumors of the ovary: a clinicopathologic analysis of 27 cases. Cancer. 1982;50(11):2438-47.

84. El-Safadi S, Stahl U, Tinneberg HR, Hackethal A, Muenstedt K. Primary signet ring cell mucinous ovarian carcinoma: a case report and literature review. Case Rep Oncol. 2010;3(3):451-7.

85. Kim JH, Cha HJ, Kim KR, Kim K. Primary ovarian signet ring cell carcinoma: a rare case report. Mol Clin Oncol. 2018;9(2):211-4

86. Yu B, Raj MS. Pseudomyxoma Peritonei. StatPearls. Treasure Island (FL): StatPearls Publishing Copyright (c) 2020, StatPearls Publishing LLC; 2020.

87. Simons M, Simmer F, Bulten J, Ligtenberg MJ, Hollema H, van Vliet S, et al. Two types of primary mucinous ovarian tumors can be distinguished based on their origin. Mod Pathol. 2020;33(4):722-33.

88. Yan F, Shi F, Li X, Yu C, Lin Y, Li Y, et al. Clinicopathological characteristics of Pseudomyxoma Peritonei originated from ovaries. Cancer Manag Res. 2020; 12:7569-78.

89. Guerrieri C, Frånlund B, Fristedt S, Gillooley JF, Boeryd B. Mucinous tumors of the vermiform appendix and ovary, and pseudomyxoma peritonei: histogenetic implications of cytokeratin 7 expression. Hum Pathol. 1997; 28(9):1039-45.

90. Ates Ozdemir D, Usubutun A. PAX2, PAX8 and CDX2 expression in metastatic mucinous, primary ovarian mucinous and Seromucinous tumors and review of the literature. Pathol Oncol Res. 2016;22(3):593-9.

91. Werling RW, Yaziji H, Bacchi CE, Gown AM. CDX2, a highly sensitive and specific marker of adenocarcinomas of intestinal origin: an immunohistochemical survey of 476 primary and metastatic carcinomas. Am J Surg Pathol. 2003;27(3):303-10.

92. Berg KB, Schaeffer DF. SATB2 as an Immunohistochemical marker for colorectal adenocarcinoma: a concise review of benefits and pitfalls. Arch Pathol Lab Med. 2017;141(10):1428-33.

93. Vang R, Gown AM, Barry TS, Wheeler DT, Yemelyanova A, Seidman JD, et al. Cytokeratins 7 and 20 in primary and secondary mucinous tumors of the ovary: analysis of coordinate immunohistochemical expression profiles and staining distribution in 179 cases. Am J Surg Pathol. 2006;30(9):1130-9.

94. Ackroyd SA, Goetsch L, Brown J, Houck K, Wang C, Hernandez E. Pancreaticobiliary metastasis presenting as primary mucinous ovarian neoplasm: a systematic literature review. Gynecol Oncol Rep. 2019;28: 109-15.

95. Chuang SC, Lee KT, Tsai KB, Sheen PC, Nagai E, Mizumoto K, et al. Immunohistochemical study of DPC4 and p53 proteins in gallbladder and bile duct cancers. World J Surg. 2004;28(10):995-1000.

96. Goldstein NS, Bassi D, Uzieblo A. WT1 is an integral component of an antibody panel to distinguish pancreaticobiliary and some ovarian epithelial neoplasms. Am J Clin Pathol. 2001;116(2):246-52.

97. Riihimäki M, Hemminki A, Sundquist K, Sundquist J, Hemminki K. Metastatic spread in patients with gastric cancer. Oncotarget. 2016;7(32):52307-16.

98. Lerwill MF, Young RH. Ovarian metastases of intestinal-type gastric carcinoma: a clinicopathologic study of 4 cases with contrasting features to those of the Krukenberg tumor. Am J Surg Pathol. 2006;30(11):1382-8.

99. Omranipour R, Abasahl A. Ovarian metastases in colorectal cancer. Int J Gynecol Cancer. 2009;19(9):1524-8.
100. Erroi F, Scarpa M, Angriman I, Cecchetto A, Pasetto L, Mollica E, et al. Ovarian metastasis from colorectal cancer: prognostic value of radica oophorectomy. J Surg Oncol. 2007;96(2):113-7.

101. Muthukrishnan S, Naganathbabu OL, Murugesan SD, Srinivasan UP, Amudhan A, Rajendran S. Krukenberg tumours from gastrointestinal cancers-analysis from a tertiary care Centre in India. J Gastrointest Oncol. 2018;9(6):1164-7.

102. Lee KC, Lin H, ChangChien CC, Fu HC, Tsai CC, Wu CH, et al. Difficulty in diagnosis and different prognoses between colorectal cancer with ovarian metastasis and advanced ovarian cancer: an empirical study of different surgical adoptions. Taiwan J Obstet Gynecol. 2017;56(1):62-7.

103. Riihimäki M, Hemminki A, Sundquist J, Hemminki K. Patterns of metastasis in colon and rectal cancer. Sci Rep. 2016;6:29765.

104. Kondi-Pafiti A, Kairi-Vasilatou E, lavazzo C, Dastamani C, Bakalianou K, Liapis A, et al. Metastatic neoplasms of the ovaries: a clinicopathological study of 97 cases. Arch Gynecol Obstet. 2011;284(5):1283-8.

105. Lee SJ, Bae JH, Lee AW, Tong SY, Park YG, Park JS. Clinical characteristics of metastatic tumors to the ovaries. J Korean Med Sci. 2009;24(1):114-9.

106. Bruls J, Simons M, Overbeek LI, Bulten J, Massuger LF, Nagtegaal ID. A national population-based study provides insight in the origin of malignancies metastatic to the ovary. Virchows Arch. 2015:467(1):79-86.

107. Li W, Wang H, Wang J. L VF, Zhu X, Wang Z. ovarian metastases resection from extragenital primary sites: outcome and prognostic factor analysis of 147 patients. BMC Cancer. 2012;12:278.

108. Skírnisdóttir I, Garmo H, Holmberg L. Non-genital tract metastases to the ovaries presented as ovarian tumors in Sweden 1990-2003: occurrence, origin and survival compared to ovarian cancer. Gynecol Oncol. 2007:105(1):166-71.

109. Moore RG, Chung M, Granai CO, Gajewski W, Steinhoff MM. Incidence of metastasis to the ovaries from nongenital tract primary tumors. Gynecol Oncol. 2004;93(1):87-91.

110. Demopoulos RI, Touger L, Dubin N. Secondary ovarian carcinoma: a clinical and pathological evaluation. Int J Gynecol Pathol. 1987;6(2):166-75.

111. Mazur MT, Hsueh S, Gersell DJ. Metastases to the female genital tract. Analysis of 325 cases. Cancer. 1984;53(9):1978-84.

112. Fujiwara K, Ohishi Y, Koike H, Sawada S, Moriya T, Kohno I. Clinical implications of metastases to the ovary. Gynecol Oncol. 1995;59(1):124-8.

113. Board WCOTE. Female genital Tumours: IARC press; 2020. p. 631

114. Garcia A, De la Torre J, Castellvi J, Gil A, Lopez M. Ovarian metastases caused by cholangiocarcinoma: a rare Krukenberg's tumour simulating a primary neoplasm of the ovary: a two-case study. Arch Gynecol Obstet. 2004:270(4):281-4

115. Gorringe KL, Cheasley D, Wakefield MJ, Ryland GL, Allan PE, Alsop K, et al. Therapeutic options for mucinous ovarian carcinoma. Gynecol Oncol. 2020; 156(3):552-60.

116. Cheasley D, Wakefield MJ, Ryland GL, Allan PE, Alsop K, Amarasinghe KC, et al. The molecular origin and taxonomy of mucinous ovarian carcinoma. Nat Commun. 2019;10(1):3935.

117. Anglesio MS, Kommoss S, Tolcher MC, Clarke B, Galletta L, Porter H, et al. Molecular characterization of mucinous ovarian tumours supports a stratified treatment approach with HER2 targeting in 19\% of carcinomas. $J$ Pathol. 2013;229(1):111-20

118. Mackenzie R, Kommoss S, Winterhoff BJ, Kipp BR, Garcia JJ, Voss J, et al. Targeted deep sequencing of mucinous ovarian tumors reveals multiple overlapping RAS-pathway activating mutations in borderline and cancerous neoplasms. BMC Cancer. 2015;15:415

119. Rechsteiner M, Zimmermann AK, Wild PJ, Caduff R, von Teichman A, Fink D, et al. TP53 mutations are common in all subtypes of epithelial ovarian cancer and occur concomitantly with KRAS mutations in the mucinous type. Exp Mol Pathol. 2013;95(2):235-41.

120. Ross JS, Ali SM, Wang K, Palmer G, Yelensky R, Lipson D, et al. Comprehensive genomic profiling of epithelial ovarian cancer by next generation sequencing-based diagnostic assay reveals new routes to targeted therapies. Gynecol Oncol. 2013;130(3):554-9.

121. Teer JK, Yoder S, Gjyshi A, Nicosia SV, Zhang C, Monteiro ANA. Mutational heterogeneity in non-serous ovarian cancers. Sci Rep. 2017;7(1):9728.

122. Hunter SM, Gorringe KL, Christie M, Rowley SM, Bowtell DD. Australian ovarian Cancer study G, et al. pre-invasive ovarian mucinous tumors are characterized by CDKN2A and RAS pathway aberrations. Clin Cancer Res. 2012:18(19):5267-77. 
123. Vereczkey I, Serester O, Dobos J, Gallai M, Szakacs O, Szentirmay Z, et al. Molecular characterization of 103 ovarian serous and mucinous tumors. Pathol Oncol Res. 2011;17(3):551-9.

124. Ryland GL, Hunter SM, Doyle MA, Caramia F, Li J, Rowley SM, et al. Mutational landscape of mucinous ovarian carcinoma and its neoplastic precursors. Genome Med. 2015;7(1):87.

125. Ohnishi K, Nakayama K, Ishikawa M, Ishibashi T, Yamashita H, Nakamura K, et al. Mucinous borderline ovarian tumors with BRAF(V600E) mutation may have low risk for progression to invasive carcinomas. Arch Gynecol Obstet. 2020;302(2):487-95.

126. Sadlecki P, Walentowicz P, Bodnar M, Marszalek A, Grabiec M, WalentowiczSadlecka M. Determination of BRAF V600E (VE1) protein expression and BRAF gene mutation status in codon 600 in borderline and low-grade ovarian cancers. Tumour Biol. 2017;39(5):1010428317706230.

127. Brockbank EC, Evans J, Singh N, Shepherd JH, Jeyarajah AR. Ovarian recurrence from a stage $1 \mathrm{~b} 1$ cervical adenocarcinoma previously treated with radical vaginal trachelectomy: a case report. Gynecol Oncol Case Rep. 2012;2(2):51-3

128. Vang R, Gown AM, Farinola M, Barry TS, Wheeler DT, Yemelyanova A, et al. p16 expression in primary ovarian mucinous and endometrioid tumors and metastatic adenocarcinomas in the ovary: utility for identification of metastatic HPV-related endocervical adenocarcinomas. Am J Surg Pathol. 2007;31(5):653-63.

129. Elishaev E, Gilks CB, Miller D, Srodon M, Kurman RJ, Ronnett BM. Synchronous and metachronous endocervical and ovarian neoplasms: evidence supporting interpretation of the ovarian neoplasms as metastatic endocervical adenocarcinomas simulating primary ovarian surface epithelial neoplasms. Am J Surg Pathol. 2005;29(3):281-94.

130. Ronnett BM, Yemelyanova AV, Vang R, Gilks CB, Miller D, Gravitt PE, et al. Endocervical adenocarcinomas with ovarian metastases: analysis of 29 cases with emphasis on minimally invasive cervical tumors and the ability of the metastases to simulate primary ovarian neoplasms. Am J Surg Pathol. 2008; 32(12):1835-53.

131. Rambau PF, Vierkant RA, Intermaggio MP, Kelemen LE, Goodman MT, Herpel $\mathrm{E}$, et al. Association of p16 expression with prognosis varies across ovarian carcinoma histotypes: an ovarian tumor tissue analysis consortium study. J Pathol Clin Res. 2018:4(4):250-61.

132. Carleton C, Hoang L, Sah S, Kiyokawa T, Karamurzin YS, Talia KL, et al. A detailed Immunohistochemical analysis of a large series of cervical and vaginal gastric-type adenocarcinomas. Am J Surg Pathol. 2016;40(5):636-44.

\section{Publisher's Note}

Springer Nature remains neutral with regard to jurisdictional claims in published maps and institutional affiliations.

Ready to submit your research? Choose BMC and benefit from:

- fast, convenient online submission

- thorough peer review by experienced researchers in your field

- rapid publication on acceptance

- support for research data, including large and complex data types

- gold Open Access which fosters wider collaboration and increased citations

- maximum visibility for your research: over $100 \mathrm{M}$ website views per year

At $\mathrm{BMC}$, research is always in progress.

Learn more biomedcentral.com/submissions 